\title{
Experimental Investigation on Thermal Performance of Double- U-tube Heat Exchanger Using CuO/water Nanofluid as Heat Transfer Fluid
}

\author{
Ruiqing $\mathrm{Du}^{1, *}$, Dandan Jiang ${ }^{1}$, and Yong Wang ${ }^{1}$ \\ ${ }^{1}$ National Centre for International Research of Low-Carbon and Green Buildings, Ministry of Science \& Technology, Chongqing \\ University, Chongqing 400045, China
}

\begin{abstract}
By applying the shallow ground energy to supply building heating and cooling, the geothermal heat exchanger systems were considered as an energy-efficient building service system. In this study, the $\mathrm{CuO} /$ water nanofluid was employed as circuit fluids of the geothermal heat exchanger system, and the thermal performance of the heat exchanger was investigated. The results showed that the heat transfer process of $\mathrm{CuO}$ /water nanofluid became stable earlier than that water. Furthermore, the heat transfer rate of nanofluid was higher than that of water when the heat transfer process plateaued.
\end{abstract}

\section{Introduction}

The global energy shortage and the necessity for environmental sustainability have motivated numerous efforts to use renewable energy in the building [1]. The geothermal heat exchangers (GHEs) systems, which employ the shallow ground energy for the energy consumption of the air condition systems, are widely used in the world [2]. The borehole thermal resistance plays a significant role in the thermal performance of GHEs system [3]. Applying nanofluids as circuit fluids can be a feasible way to reduce the borehole thermal resistance $[2,4]$.

Numerous previous studies have forced on using nanofluid in GHEs systems. Sergio Bobbo et al. [5] use the Mouromtseff number to evaluate the thermal performance of $\mathrm{Al}_{2} \mathrm{O}_{3}$ /water nanofluid applied in the geothermal system. They found that the nanofluid with a concentration higher than $3 \mathrm{wt} \%$ can be a reasonable option for the geothermal application. Diglio et al. [6] numerically investigated different types of nanofluid used in the GHEs system The results showed that the $\mathrm{Cu}$-based nanofluid with the volumetric concentration of $0.1 \%$ was characterized by the lower $(3.8 \%)$ borehole thermal resistance and the higher $(6 \%)$ pressure drop of GHE. Dan Sui et al. [7] conducted a numerical investigation on the effect of nanofluid on the energy extraction capability of the geothermal double pipe heat exchanger. The results showed that nanofluid extracted $11.24 \%$ more energy, in comparison to the base fluid. Mahdi Daneshipour et al [8]. numerically investigate the thermal performance of the $\mathrm{CuO} /$ water and $\mathrm{Al} 2 \mathrm{O} 3$ /water nanofluid in GHE. They found the $\mathrm{CuO} /$ water nanofluid was characterized by a higher heat transfer rate and higher pressure drop than that of $\mathrm{Al} 2 \mathrm{O} 3$ /water nanofluid.
Although the numerical models are well developed to study the effect of particle type and boundary conditions of nanofluids on the heat transfer of GHE, few of them consider an experimental investigation. In this study, an experiment was conducted to investigate the effects of the nanofluid on the heat transfer and thermal performance of GHE. The results can contribute to the design of the GHE system using nanofluid as circuit fluid.

\section{Experimental setup}

The schematic of the experimental setup employed in the present study was shown in Figure 1 and the photo of the experiment setup were shown in Figure 2. Two geothermal heat exchangers were installed in a sandbox $(0.8 \mathrm{~m} \times 0.5 \mathrm{~m} \times 0.58 \mathrm{~m})$ and buried in the sand. Two tanks with electrical heater were used to heat and store fluids. The circuit fluid if \#1 heat exchanger was $\mathrm{CuO} /$ water nanofluid, and the circuit fluid of \#2 heat exchanger was pure water. The detail parameters of the double-U-tube heat exchanger were shown in Table 1.

Table 1. The detail parameters of double-U-tube heat exchangers

\begin{tabular}{cc}
\hline Parameter & Value $(\mathbf{m})$ \\
\hline Total length of each double-U-tube & 2.5 \\
Wall thickness & 0.002 \\
Inner diameter & 0.01 \\
Distance between centers of pipes & 0.092 \\
\hline
\end{tabular}

Two flow meters were used to measure the flow rate of fluids, and the flow rate was controlled at $0.354 \mathrm{~m} / \mathrm{s}$ by two valves. The measuring range and uncertainty of flow

\footnotetext{
* Corresponding author: drq697095@sina.com
} 
meter was $0.04-0.4 \mathrm{~m}^{3} / \mathrm{h}$ and $0.2 \%$, respectively. Ten platinum thermal resistors were installed at the inlet and outlet of tubes, and the sandbox wall to monitor the temperature variation. Figure 3 shows the locations of two heat exchangers and all measuring points. All data of temperature were recorded by the data logger system. The constant heat load $(50 \mathrm{~W})$ was inputted into the fluid.

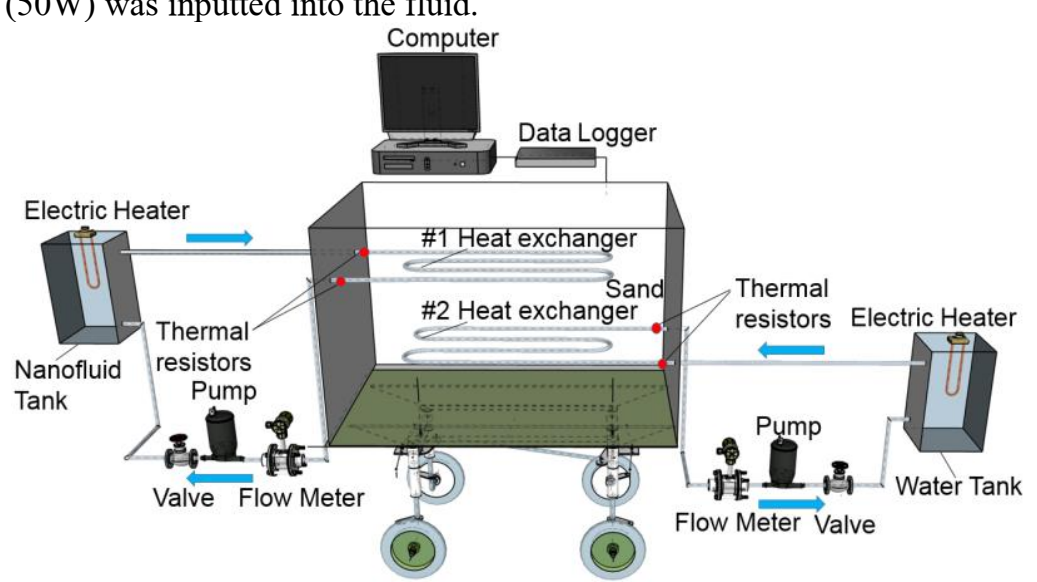

Figure 1. Schematic diagram of the experimental system.

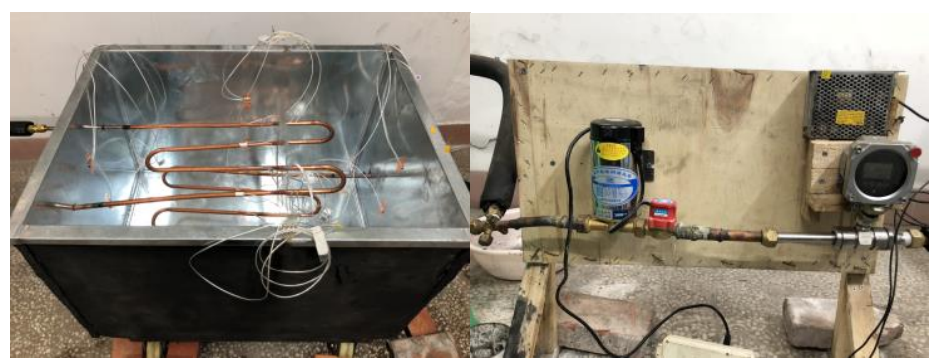

(a)

(b)

Figure 2. The photo of the experimental system. (a)the heat exchangers and temperature measuring system (b) pump and flow meter

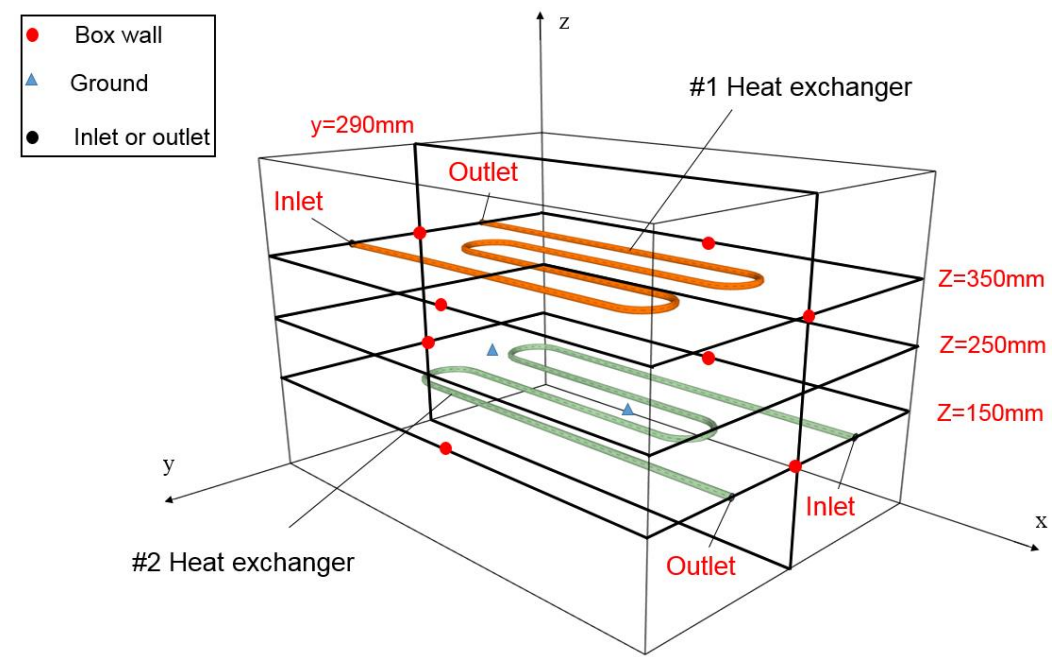

Figure 3. The locations of heat exchangers and measuring points.

\section{Result and discussion}

The average soil temperature was obtained by the following equation:

$$
\Delta T=\frac{\sum_{1}^{n} T_{i}}{n}
$$

The time of the experiment was $2 \mathrm{~h}$. Two power metering sockets were used to measuring the power umption of pumps, and the uncertainty was $1 \%$.

The thermal properties of the materials used in the experiment obtained from our previous studies [9-12] were shown in Table 2. 
Table 2. The thermophysical properties of materials

\begin{tabular}{cccc}
\hline Physical parameters & Nanofluid & Cu & Sand \\
\hline $\begin{array}{c}\text { Density, } \rho,\left(\mathrm{kg} / \mathrm{m}^{3}\right) \\
\text { Specific heat, } C_{P}, \quad(\mathrm{~J} / \mathrm{kg} \bullet \mathrm{K})\end{array}$ & 1026 & 8978 & 1953.39 \\
Thermal conductivity, $\lambda,(\mathrm{W} / \mathrm{m} \bullet \mathrm{K})$ & 4070 & 381 & 1348 \\
Dynamic viscosity, $\mu,(\mathrm{kg} / \mathrm{m} \bullet \mathrm{s})$ & 0.67 & 387.6 & 1.13 \\
\end{tabular}

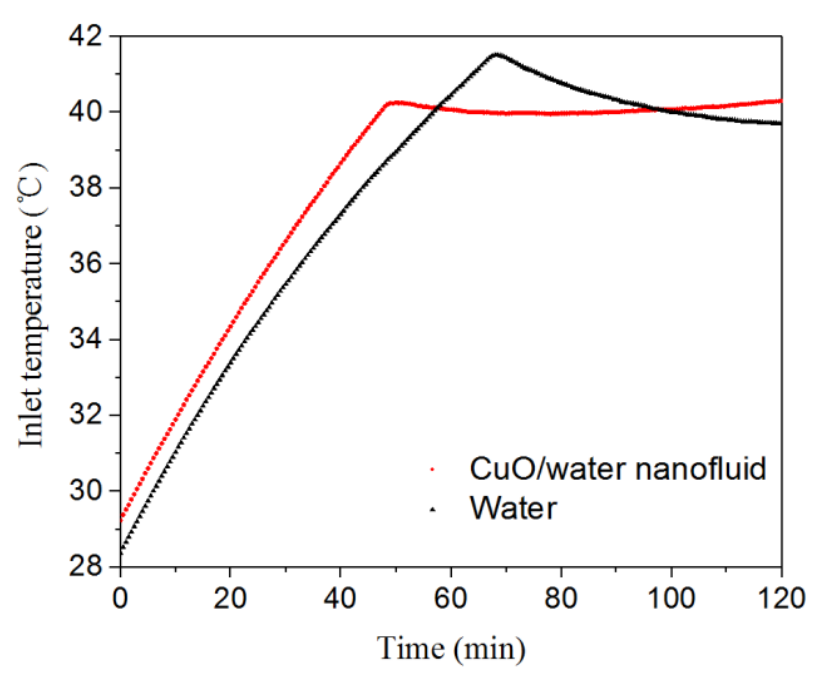

(a)

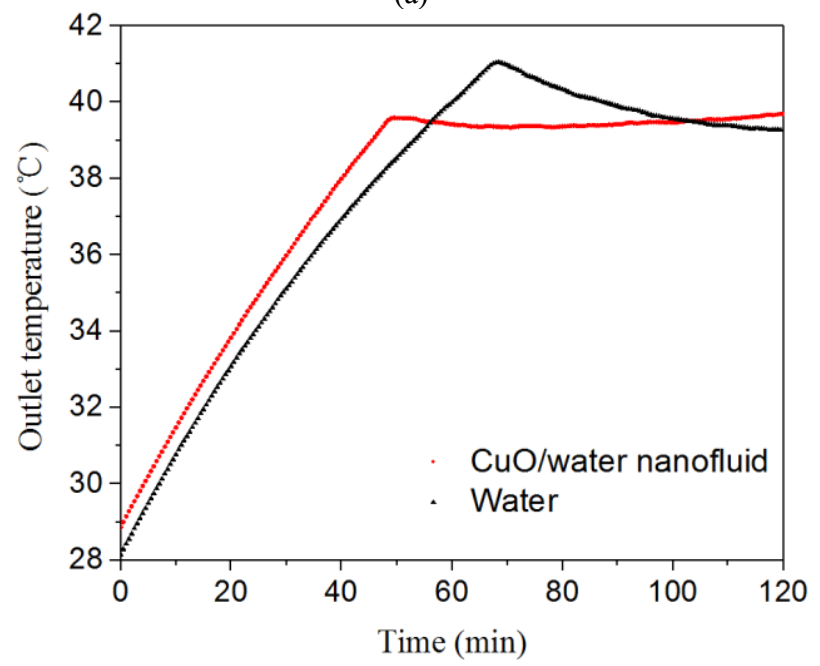

(b)

Figure 4. (a) The inlet temperature of $\mathrm{CuO} /$ water nanofluid and water (b) The outlet temperature of $\mathrm{CuO} /$ water nanofluid and water

Figure 4 illustrates the inlet and outlet temperature of $\mathrm{CuO} /$ water nanofluid and water. The thermal conductivity of nanofluid was higher than water. Therefore, the inlet temperature of nanofluid increased with a higher gradient than water, when the same amount of heat load was inputted into two GHE systems (Figure 4 (a)).

The outlet temperature of nanofluid became stable after $45 \mathrm{~min}$, while the number of water became stable after 100min. The outlet temperature of nanofluid became stable earlier than that of water due to the higher thermal conductivity of nanofluid and the faster heat transfer process (Figure 4 (b)).

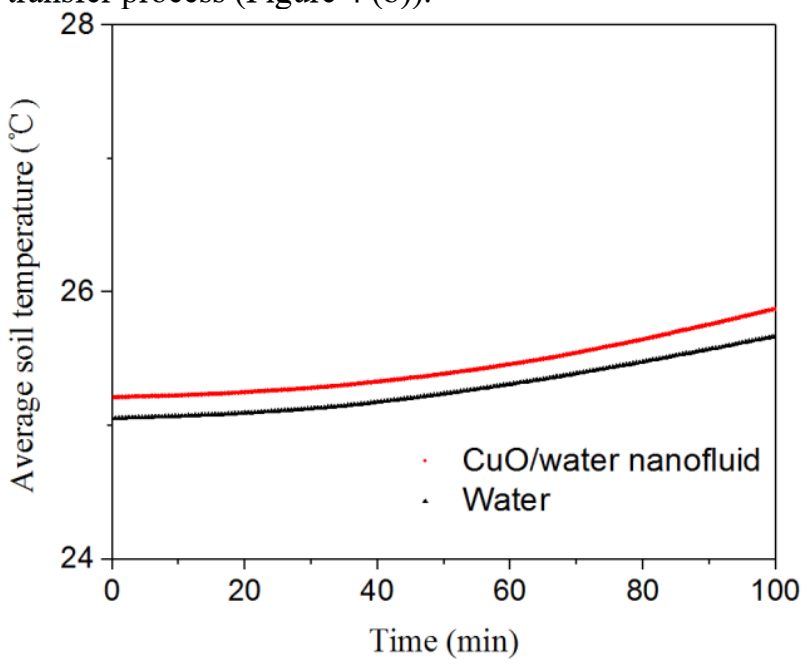

Figure 5. The soil temperature near heat exchangers using nanofluid and water

Figure 5 shows the average soil temperature for the same levels as the $\# 1$ heat exchanger $(\mathrm{CuO} /$ water nanofluid) and \#2 heat exchanger (water). The soil temperature for nanofluid and water increased slightly ( $0.93 \%$ for nanofluid and $0.98 \%$ for water) in the first hour due to the energy storage capability of soil. In the second hour, when the heat transfer process reached a plateau, the number for nanofluid increased with a higher gradient $(2.54 \%$ for nanofluid and $2.13 \%$ for water) and was higher than that of water, which means more heat was released into ground. That can be explained by the higher thermal conductivity and the higher heat transfer rate of nanofluid.

\section{Conclusion}

In this study, an experimental GHE system was constructed in Chongqing, China. The $\mathrm{CuO} /$ water nanofluid was used as circuit fluid in the systems and compared with water. The thermal performance nanofluid in the GHE was investigated. The inlet and outlet of nanofluid increased with a higher gradient and became stable earlier than that of water due to the higher thermal conductivity. Meanwhile, the average temperature shows that nanofluid had a higher heat transfer rate than water. 


\section{Acknowledgements}

The authors gratefully acknowledge the financial support from the National Natural Science Foundation of China (51178482).

\section{References}

1. Ahmia, M. 42, 189-193 (2015).

2. Faizal, M., Bouazza, A., Rao, M. S. Renewable \& Sustainable Energy Reviews 57, 16-33 (2016).

3. Narei, H., Ghasempour, R., Noorollahi, Y. Energy Conversion \& Management 123, 581-591 (2016).

4. Bianco, V., Chiacchio, F., Manca, O., Nardini, S. Applied Thermal Engineering 29, 3632-3642 (2009).

5. Bobbo, S., Colla, L., Barizza, A., Rossi, S., Fedele, L., (2016).

6. Diglio, G., Roselli, C., Sasso, M., Jawali Channabasappa, U. Geothermics 72, 112-123 (2018).

7. Sui, D., Langåker, V. H., Yu, Z. Energy Procedia 105, 5055-5060 (2017).

8. Daneshipour, M., Rafee, R. International Communications in Heat and Mass Transfer 81, 3441 (2017).

9. Li, W., Li, X., Wang, Y., Du, R., Tu, J. Renewable Energy 141, 340-348 (2019).

10. Li, W., Li, X., Peng, Y., Wang, Y., Tu, J. Applied Thermal Engineering 135, 228-237 (2018).

11. Li, W., Li, X., Peng, Y., Wang, Y., Tu, J. Renewable Energy 147, 620-629 (2020).

12. Li, W., Li, X., Du, R., Wang, Y., Tu, J. Geothermics 77, 75-82 (2019). 